\title{
SIMULATION MODEL OF PRODUCTION AS TOOL FOR INDUSTRY 4.0 IMPLEMENTATION INTO PRACTICE
}

\author{
Erika Sujova, Helena Cierna, Roman Bambura \\ Technical University of Zvolen, Slovakia \\ erika.sujova@tuzvo.sk, helena.cierna@tuzvo.sk, bambura.r@gmail.com
}

\begin{abstract}
The article deals with the process of Industry 4.0 implementation into practice through simulation. The aim of the paper is to point out the possibilities of computer simulations in creating models of real production plants. The research is carried out as a case study of a production plant in a Slovak machine-building company dealing with the components for the automotive sector production. The process of creating a simulation model of a production line consisting from two CNC machining centers is presented. Subsequently the output statistical characteristics of the real-time model are obtained from the simulation model. The simulated model of the manufacturing plant and its components is the basis for the comprehensive deployment of Industry 4.0 strategy into practice. We expect that in the coming years there will be an increased demand for creation of simulation models of manufacturing systems by modern enterprises that will try to implement the Industry 4.0 strategy and thus increase its competitiveness. The results of our simulation models have shown that the production line is not efficient enough and it will be necessary to create a more detailed simulation model with major adjustments. More than $60 \%$ of the overall process time mainly consists of waiting and blocked time, which leads to inefficient production with the machining time only $38 \%$ at maximum. The most efficient station was Stama with $73.67 \%$ of the working time, but we expect to increase the production for this station as well with some changes to the whole production line.
\end{abstract}

Keywords: simulation model, Industry 4.0, production line.

\section{Introduction}

Optimization of the production processes is currently one of the most common optimization tasks in production. The complexity and demanding of the market environment force businesses to pay particular attention to improving the operating conditions [1]. The enterprise must work in such a way that the input-output transformation proceeds with optimal consumption of production inputs, the optimal choice of production processes, resources and optimal utilization of production capacity [2].

Development in the industry has been heading by improving the production processes from automation to their digitization. The latest trend in businesses is implementation of the Industry 4.0 strategy, which predicts the future development of digital production. Many authors deal with the characteristics and the definition of the concept of Industry 4.0.

Bauer (2014) has defined Industry 4.0 like an intelligent real-time, horizontal and vertical integration of humans and machines with objects and information and communication technology systems ("digitalization") to enable a flexible and dynamic management of complex systems [3].

Industry 4.0 philosophy and the associated method of digital factory require a wide range of tasks and skills to be managed for their successful application and efficient operating. One of the key competencies for their reliable operation is mastering computer simulation of various logistics processes that take place within the enterprise [4].

Industry 4.0 in manufacturing is about combining cyber-physical systems with industrial automation systems. This integration of systems so different in nature aims to create context-aware factories, in which people and machines are in real-time alignment [5].

Based on the definition of Industry 4.0 introduced above, we can identify three levels of implementation of the technology from a production perspective:

1. Vertical integration: in the context of production and automation, this concept refers to the integration of diverse ICT systems into different hierarchical levels, from the very basic ones (e.g., sensors and actuators) to the highest levels of production management, execution, planning and scheduling. This level of integration supports manufacturing processes, making them more flexible.

2. Horizontal integration: this level includes the integration of ICT technologies into mechanisms and agents involved in the different stages of the manufacturing processes and business planning; 
this means exchanging energy and information within a company (e.g., input and output logistics, production and commercialization), and between companies and entities (value networks) [6].

3. Circular integration: vertical and horizontal integrations are joined to link the end user and the product life cycle [7]. This integration ends the production loop; therefore, the whole end-to-end digitalization is fully achieved, from the initial design stages, to planning and manufacturing, the logistics and resources management mechanisms and, finally, to the end user and product related services [8].

Tecnomatix Plant Simulation (TPS) is a simulation tool that enables you to create digital system models to help you define the system characteristics and optimize performance. Digital models allow us to experiment with scenarios without disturbing the existing production being able to use them in the planning process long before the changes are introduced into the production process. Extensive analytical tools, such as narrow space analyses, statistics and graphs allow you to evaluate different production scenarios. Simulation of results provides the information needed for quick and reliable decisions in the initial stages of production planning. Using TPS, we can model and simulate manufacturing systems and their processes. In addition, TPS allows you to optimize the material flow, resource utilization, and logistics for levels of production plant planning, through local plans to specific lines [9].

TPS simulations are used with high efficiency to optimize production and minimize the process work. Simulation models make it possible to take into account the internal and external supply chains, production resources and business processes, allowing you to analyse the impacts of different production variants. It is possible to evaluate different production lines, control strategy and verify the synchronization of lines. The system allows to define different material flows and determine their effect on the line and its performance. Control rules are selected from libraries and can be further modelled as highly sophisticated controls. Optimization can also be done automatically using algorithms in TPS. This is useful, if there are a number of system parameters and limitations and it is difficult to find the optimal solution. Algorithms optimize the system parameters for a number of limitations, such as throughput, inventory, resource usage, and delivery times. These solutions are further evaluated using simulations and are interactively searching for the optimal solution using the balance line and the different dose sizes. TPS analytical tools make it easy to interpret the simulation results using statistical analysis graphs for the use of balancing items, machines and staff. It is possible to create extensive statistics and charts to support the dynamic performance analysis including the line load, failures, inactivity and repair time [10].

The article deals with optimization of processes running on a real production line using the computer simulation method. The result of this thesis is the process of creating a simulation model of a production line consisting of two CNC machining centers. Simulation results are also expressed quantitatively, using statistical data that characterize the effectiveness of the solution. The research is a part of the KEGA 011TU Z-4/2017, which deals with integration of progressive information technologies into education.

\section{Materials and methods}

\subsection{Characteristics of computer simulations as a tool for line optimization}

Simulation of the production line in the TPS environment is an effective method for solving our research objectives aimed at analysing the line processes efficiency. The outputs of the preformed simulation are resource statistics, from which we can determine the cost of individual workstations and thus determine the effectiveness of the solution.

\subsection{Simulation procedure}

In order to create a simulation model of a production line consisting of $2 \mathrm{CNC}$ machining centers, it was necessary to obtain relevant production data that characterize the ongoing production processes in the first step. Additionally, we created simulation models of two per partes CNC machining centres that were merged together to the complete model of the LN1 production line. Subsequently, in the case study, statistical characteristics outputs of the real model for the machining (production) line were generated. 
The simulation model of the machining line for brake components consisting of two CNC machining centres is shown in Fig. 1. The simulation model illustrates the manufacturing processes for three types of components with real processing times and processing sequences within one working day [11].

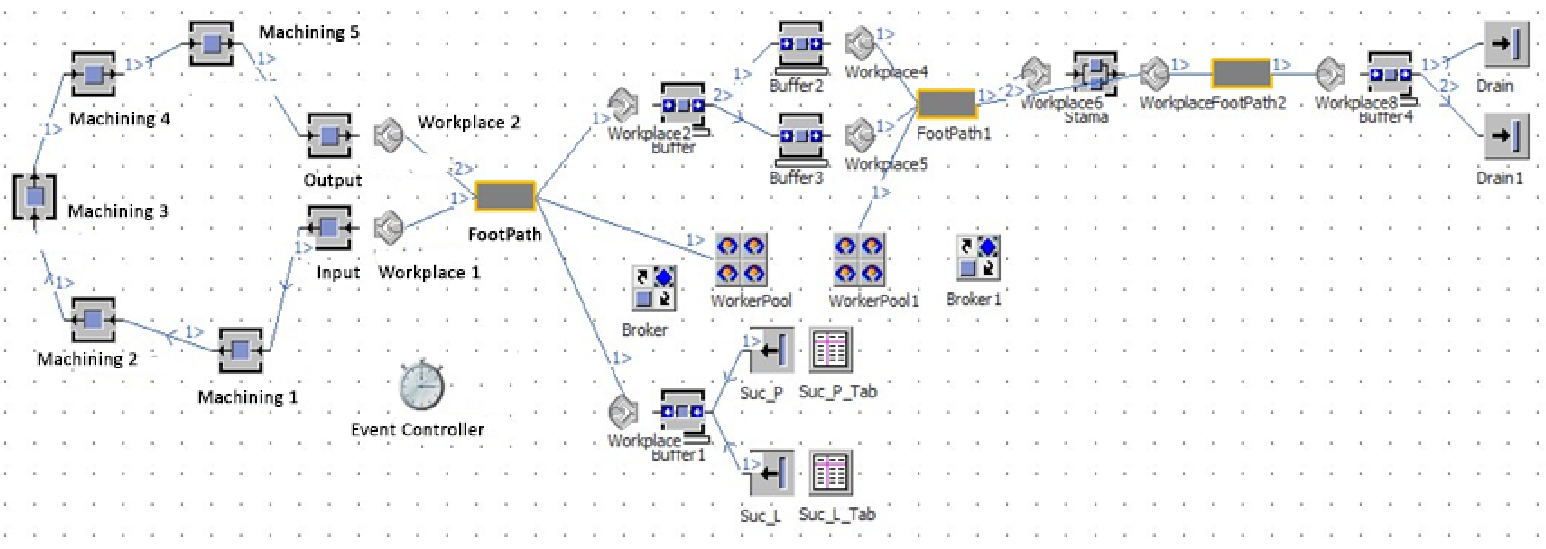

Fig. 1. Complete simulation model of production line consisting of 2 CNC machining centres (TPS)

Table 1

Working times for S1 machining used in simulation

\begin{tabular}{|c|c|c|c|}
\hline \multirow{2}{*}{ Machining } & Operation & \multirow{2}{*}{\begin{tabular}{|c|} 
Suc_1P \\
17.7 \\
\end{tabular}} & \multirow{2}{*}{\begin{tabular}{|c|} 
Suc_1L \\
17.7
\end{tabular}} \\
\hline & Input and Output & & \\
\hline \multirow{3}{*}{ S1 Machining 1} & Drilling absorber holes & 14 & \multirow{3}{*}{31.8} \\
\hline & Roughing the piston hole & 13 & \\
\hline & Other & 4.8 & \\
\hline \multirow{3}{*}{ S1 Machining 2} & Milling of flange & 24 & \multirow{3}{*}{34.8} \\
\hline & Recessing. drilling holes & 5.6 & \\
\hline & Other & 5.2 & \\
\hline \multirow{4}{*}{ S1 Machining 3} & Machining brake pad wall & 12.3 & \multirow{4}{*}{28.1} \\
\hline & Roughening of duster & 5.5 & \\
\hline & Milling guide surfaces for brake pad & 5 & \\
\hline & Other & 5.3 & \\
\hline \multirow{4}{*}{ S1 Machining 4} & Seal ring groove machining & 4.2 & \multirow{4}{*}{30.2} \\
\hline & Duster machining & 7.2 & \\
\hline & Sealing groove machining & 12.6 & \\
\hline & Other & 6.2 & \\
\hline \multirow{4}{*}{ S1 Machining 5} & Chamfering and drilling of connection holes & 8.7 & \multirow{4}{*}{33.8} \\
\hline & Thread cutting of connection holes & 8.1 & \\
\hline & Reaming of piston hole and bearing bush inserting & 14.1 & \\
\hline & Other & 2.9 & \\
\hline & & Total & 176.4 \\
\hline
\end{tabular}

Note: Suc_1P and Suc_1L from Table 1 refer to the 2 types of the workpiece.

\section{Results and discussion}

The aim of our research is to highlight the possibilities of applying the Industry 4.0 principles to current production systems. Digitalization procedures of a company within Industry 4.0 principles are implemented, in addition to other methods by simulation of manufacturing systems, which is indicated in the case study. The simulation output is a simulation model of the production system, which is a 
digital counterpart of real production processes of a CNC machining line. Simulation analysis from TPS software provides a lot of information about behaviour and efficiency of production processes, which are presented as tables of graphical statistical outputs. Statistical simulation outputs serve to compare the current status of the production line with the proposed optimized production line, where we plan to implement improvements.

Simulation time is set to 8 hours i.e. 1 working day, after completion of simulation TPS software generates a table with basic statistical evaluations of the process efficiency for individual workstations shown in Table 2, which shows the working time, waiting time, blocked time and fault time.

Table 2

Basic statistical evaluations of process efficiency for original production line workstations

\begin{tabular}{|c|c|c|c|c|c|}
\hline Workstation & $\begin{array}{c}\text { Working } \\
\text { time } \\
\mathbf{\%}\end{array}$ & $\begin{array}{c}\text { Waiting time } \\
\mathbf{\%}\end{array}$ & $\begin{array}{c}\text { Blocked time } \\
\mathbf{\%}\end{array}$ & $\begin{array}{c}\text { Fault time } \\
\mathbf{\%}\end{array}$ & $\begin{array}{c}\text { Overall } \\
\text { process } \\
\text { time \% }\end{array}$ \\
\hline S1 Machining 1 & 35.30 & 21.00 & 41.97 & 1.72 & 100.00 \\
\hline S1 Machining 2 & 37.90 & 21.40 & 39.97 & 0.73 & 100.00 \\
\hline S1 Machining 3 & 30.98 & 23.66 & 45.36 & 0.00 & 100.00 \\
\hline S1 Machining 4 & 34.76 & 21.78 & 43.46 & 2.10 & 100.00 \\
\hline S1 Machining 5 & 34.18 & 21.74 & 42.75 & 1.33 & 100.00 \\
\hline S2 Stama & 73.67 & 3.62 & 21.51 & 1.20 & 100.00 \\
\hline
\end{tabular}

Another option offered by the TPS simulation software is to generate statistical results in various graphical outputs. Statistical methods are incorporated in TPS software and statistical evaluations are performed automatically through this software. The column chart in Fig. 2 created in TPS is based on selected processes. We present them in the original format. The charts are based on the data from Table 2. The column chart illustrates the efficiency of the selected processes and the inefficient times for individual workstations.

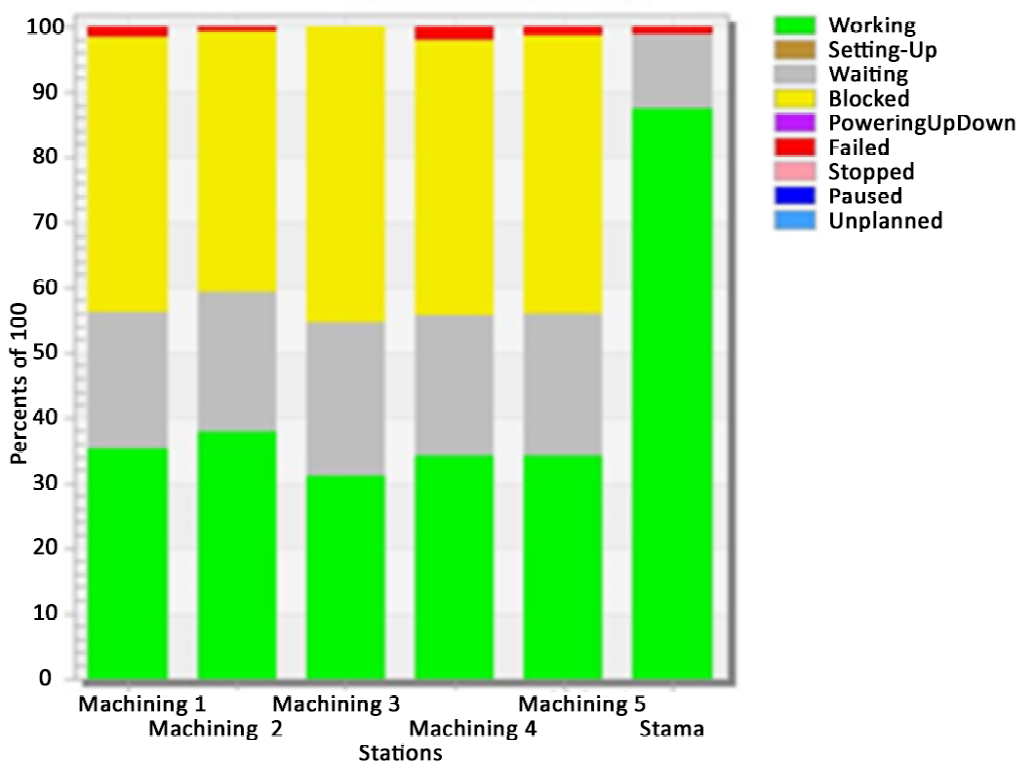

Fig. 2. Process efficiency column chart for production model (TPS)

The working time, waiting time, blocked time, fault time and overall process time for the workstations are shown as percentages in Table 2 and as a graph in Fig. 2. The results show that the workstations operate from $30.98 \%$ to $37.90 \%$. The majority of the time was not efficient, as we can evaluate from the results, and was spent for waiting for the material, which was from $21 \%$ up to $23.66 \%$, or machining was blocked $39.97 \%$ to $45.36 \%$ of the overall process time. Only $2.1 \%$ of the process time was fault time. The Stama station working time efficiency was at $73.67 \%$, but some minor changes can help increase the working time and decrease the blocked time to a lower rate 
compared to the current $21.51 \%$. Therefore, this information and data will be used to create a more complex and detailed model for future improvement of the working time.

TPS provides high flexibility in changing the workstation capacity, number of products, materials, transport and machining speed. Therefore, these data can be implemented into created models, which allow to create more detailed models with automatic statistic recalculation. Such information and data can be used for various areas of business processes by technologists, production planners or economists. The aim of the research was to initially analyse the efficiency of the proposed production line.

Focus of Industry 4.0 principles is to increase the operational efficiency, resulting from the principle of digitization and fluidity of the data flow, as well as from the new concept of connecting preparatory phases of production with actual production [12].

The results obtained by our research as an output from the simulation model created in TPS help the analysed organization evaluate the efficiency of the manufacturing processes. After changing the parameters in the model (e.g., change of production times), we are able to show the results of the change in the virtual model in terms of utilization of individual workplaces and the efficiency of individual processes.

\section{Conclusions}

Optimization of production systems by means of digitization is currently focused on reducing the production time, costs, increasing the quality of production, addressing the ergonomics of workplaces with a regard to eliminate the workers' health and safety risks. The result is significant increase of operational efficiency of production. The aim of our research is to prove this paradigm.

Our research shows that implementation of simulation models for the management of the current production systems is very useful; it provides a quantity of data and statistics that accurately reflect the actual situation in the production, which allow the application of innovations in the model, and preassess their impact on the efficiency of production processes. In created simulation models, we can fairly easy change the input parameters of the production, which allows us to respond quickly to customer requirements and to flexibly generate enough data to produce the expected results of the unrealized production presented in already prepared simulation models. In our case study we presented a methodical approach to simulation of a production line consisting of two CNC machining centres. A digital counterpart of real production line was created as a simulation model with production processes that correspond exactly to the production plan entered into production during the simulation. The optimization solution results generation into the statistical characteristics of the model, present the efficiency of selected processes and the ineffective times of individual workstations in the production line. The results show that individual workstations process time is not efficient. More time was spent as the waiting time or machining was blocked. Therefore, the working time was only up to $37.90 \%$ of the overall process time and other non-efficient times consist of more than $60 \%$ of the overall process time. Stama station was most efficient with $73,67 \%$ of the working time, but the station was blocked $21.51 \%$ of the overall process time. Therefore, some minor changes can enhance production for that station as well. These data will be used in future to create a more efficient simulation model to enhance production and to decrease the waiting, blocked and fault time to minimum.

\section{Acknowledgements}

The authors would like to thank the Agency KEGA for the support of the KEGA 011TU Z-4/2017 project "Integration of progressive information technologies and soft-skills in education programs focusing on management of production processes". This article was created as a part of the project.

\section{References}

[1] Alavi, H., Habek, P. Optimizing outcome in the university - industry technology transfer projects. Management Systems in Production Engineering. Vol. 22, 2016, No.2, pp. 94-100.

[2] Simanova L., Gejdos, P. The process of monitoring the quality costs and their impact on improving the economic performance of the organization. Enterprise Management, Vol. 3, 2016, pp. 172-179. 
[3] Bauer, W., Schlund, S., Marrenbach, D., Ganschar, O.Industrie 4.0 VolkswirtschaftlichesPotenzialfür Deutschland. Studie. 2014.[online] [12.02.2019]. Available at: https://www.produktionsarbeit.de/content/dam/produktionsarbeit/de/documents/Studie-Industrie4-0-Volkswirtschaftliches-Potential-fuer-Deutschland.pdf

[4] Neradilova, H., Fedorko, G. Simulation of the supply of workplaces by the AGV in the digital factory. TRANSCOM 2017: International scientific conference on sustainable, modern and safe transport. Procedia Engineering. 2017,doi: 10.1016/j.proeng.2017.06.110. pp. 638-643

[5] Prause, M., Weigand, J. Industry 4.0 and Object-Oriented Development:Incremental and Architectural Change. Journal of technology management \& innovation. ISSN 0718-2724. 2016. Vol. 1, Issue 2, 2016. pp. 104-110.

[6] Dado, M., Kotek, L., Hnilica, R., Tůma, Z. The application of Virtual Reality for hazard identification training in the context of machinery safety: A preliminary study. Manufacturing Technology. Vol. 18, Issue 5, 2018, pp. 732-736

[7] Bialy, W.,Ruzbarsky, J. Breakdown cause and effect analysis. Case study. Management Systems in Production Engineering, Vol. 26, No.2, 2018. pp. 83-87. p-ISSN 2299-0461.

[8] Diez-Olivan, A., Del Ser, J., Galar, D., Sierra, B. Data fusion and machine learning for industrial prognosis: Trends and perspectives towards Industry 4.0. Information Fusion 50 (2019). ISSN 1566-2535. https://doi.org/10.1016/j.inffus.2018.10.005, pp. 92-111.

[9] TPS. Tecnomatix Plant Simulation, [online] [06.02.2019]. Available at: http://4dsysco.com/siemens-plm/tecnomatix/tecnomatix-plant-simulation

[10] Plant Simulation, Plant, line and process simulation and optimization, [online] [06.02.2019]. Available at: https://www.plm.automation.siemens.com/global/en/

[11] Urban, P. Process line optimization usingTecnomatix Plant Simulation. 2018. The bachelor thesis. TU voZvolene, FEVT.

[12] Trebuna, P., Markovic, J.,Kliment, M., Halcinova, J. Modeling in Industrial Engineering, Faculty of Mechanical Engineering, TU in Košice, 2015, ISBN 978-80-553-1953-7. 